\title{
Secular trend in dietary patterns of Iranian adults from 2006 to 2017: Tehran lipid and glucose study
}

Maryam Aghayan ${ }^{1}$, Golaleh Asghari ${ }^{1,2^{*}}$, Emad Yuzbashian ${ }^{1}$, Maryam Mahdavi $^{3}$, Parvin Mirmiran ${ }^{1 *}$ (D) and Fereidoun Azizi ${ }^{4}$

\begin{abstract}
Background: Based on data regarding nutrition transition in the Middle East and North Africa, this study aim to investigate the general structure and secular trend of dietary patterns reported from the Tehran Lipid and Glucose Study (TLGS) and adherence to these dietary patterns among Iranian population from 2006 till 2017.

Methods: We investigated on four examination waves of TLGS, including wave 1 (2006-2008), wave 2 (2009-2011), wave 3 (2012-2014), and wave 4 (2015-2017), using a validated and reliable food frequency questionnaire.

Generalized Estimating Equations was used to assess secular trends in anthropometric, biochemical, and dietary variables across the study period. To identify general structure and secular trend of dietary patterns during each waves, principle component analysis (PCA) and K-mean cluster analysis were used, respectively.
\end{abstract}

Results: After adjusting for potential confounders including age, sex, body mass index, and total energy intake, the carbohydrate and protein intake gradually increased and the total fat intake decreased during study period ( $P$ value< 0.001 ), although total energy intake remained stable. During the study period, participants consumed noticeably less refined grains, solid fat, dairy products, and simple sugars. Snack and dessert consumption increased and meat intakes showed no significant changes during a decade (all $P$-values $<0.001$ ). Three dietary patterns extracted using PCA, included: Healthy dietary pattern characterized by higher intakes of vegetable, fruit, dairy products, liquid oil, nuts and seeds, and honey and jam; Western dietary pattern featured by refined grain, solid fat, meat, snack and dessert, potato, and soft drink, and the Mixed dietary pattern, highlighted by tea and coffee, and simple sugar. Based on cluster analysis, $27.8 \%$ of participants in wave 4 followed a Western dietary pattern, and $34.1 \%$ followed the Mixed dietary pattern. The Healthy dietary pattern was stable among the study population during the last decade.

Conclusions: The structure and the type of foods that participants preferred to eat changed since 2006, a new secular trend in dietary patterns, including a stability of Healthy dietary pattern, a decline of the Western dietary pattern and an increase in the Mixed dietary pattern was obsereved in our investigation.

Keywords: Dietary patterns, Secular trend, Nutrition transition, Factor analysis, Adults, TLGS

\footnotetext{
*Correspondence: G_asghari@hotmail.com; mirmiran@endocrine.ac.ir; parvin.mirmiran@gmail.com

'Nutrition and Endocrine Research Center, Research Institute for Endocrine

Sciences, Shahid Beheshti University of Medical Sciences, P.O. Box:

19395-4763, Tehran, Iran

Full list of author information is available at the end of the article
}

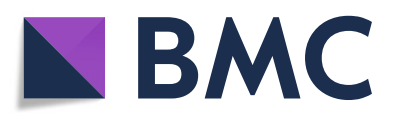

() The Author(s). 2020 Open Access This article is licensed under a Creative Commons Attribution 4.0 International License, which permits use, sharing, adaptation, distribution and reproduction in any medium or format, as long as you give appropriate credit to the original author(s) and the source, provide a link to the Creative Commons licence, and indicate if changes were made. The images or other third party material in this article are included in the article's Creative Commons licence, unless indicated otherwise in a credit line to the material. If material is not included in the article's Creative Commons licence and your intended use is not permitted by statutory regulation or exceeds the permitted use, you will need to obtain permission directly from the copyright holder. To view a copy of this licence, visit http://creativecommons.org/licenses/by/4.0/ The Creative Commons Public Domain Dedication waiver (http://creativecommons.org/publicdomain/zero/1.0/) applies to the data made available in this article, unless otherwise stated in a credit line to the data. 


\section{Introduction}

Nutrition transition in the Middle East and North Africa (MENA) region, has been a result of the rapid demographic changes, social development, and urbanization $[1,2]$, demonstrated as a set of gradual dietary changes from healthy diets to a pattern of westernized foods [3]. According to the Global Burden of Disease (GBD) report, although the mean daily intake of some healthy foods including fruit, vegetables, fiber, and legume increased in the MENA region from 1990 to 2017, the burden of chronic diseases such as hypertension, type 2 diabetes, and cardiovascular disease rose, simultaneously [4-6], a finding indicating that concentrating on a single food per se cannot explain the link between fast rising trend in non-communicable diseases in the current decade and higher intakes of some healthy foods.

People eat meals consisting of foods in different combinations. As there are several synergistic and adversary interactions between nutrients, studying dietary patterns is a better approach to identify a holistic view of eating behaviors of populations rather than focusing on the single dietary factor $[7,8]$. Principal component analysis (PCA) is one of the most commonly used approach to derive dietary patterns, which is based on data reduction methods and provide a more complete picture of diets for the study population.

Changes in dietary patterns among population have been a subject of growing interest in various regions [912]. Despite the rapid economic changes in China, dietary patterns of the Chinese population remained relatively stable from 1991 to 2009 [9]. Lim et al. demonstrated that approximately $40 \%$ of participants still follow a traditional Korean diet which remained relatively stable since 1998 to 2010; however, the secular trend of Western dietary patterns decreased from $30 \%$ in 1998 to $10 \%$ in 2010 [10].

As dietary intake is one of the main contributors to chronic diseases, a robust, quantitative understanding of dietary patterns is imperative for designing strategies to reduce national and global diet-related disorders [13]. Based on the important impact of globalization and urbanization on dietary pattern alterations as well as increased incidence of chronic diseases in the MENA, this study has two main objectives; first, to investigate the general structure and secular trend of dietary patterns extracted from the Tehran Lipid and Glucose Study (TLGS) and second, adherence to these dietary patterns among Iranian population from 2006 till 2017.

\section{Methods}

\section{Study population}

This study was conducted within the framework of the TLGS, a long term prospective population study initiated in 1998 to determine the prevalence of non- communicable disease risk factors and its outcomes among the urban Tehranian population; detailed have been previously described [14]. Briefly, the first examination was initiated in 1999 among 15,005 people, aged $\geq 3$ years from district 13 of Tehran using the multistage cluster random sampling method. Participants undergoing a follow-up visit every 3 years, and data on any changes in demographic, anthropometric, reproductive and metabolic features and laboratory assessments were collected. The baseline examination was a cross-sectional study conducted from 1999 to 2001, and wave II (2002-2005), III (2006-2008), IV (2009-2011), V (2012-2014), and VI (2015-2017) were prospective follow-up waves. From the third examination wave of the TLGS (2006-2008), dietary assessment was begun on 3462 participants, who were randomly selected from 12,523 examined participants.

For the present study we investigated on four examination waves of TLGS, including waves 1 (2006-2008), 2 (2009-2011), 3 (2012-2014), and 4 (2015-2017). In each examination wave, we included all adults aged $\geq 18$ years with complete dietary data for at least two waves. We excluded those who had only specific dietary changes, such as diet therapy for hypertension, dyslipidemia, and hyperglycemia (3372 participants excluded), furthermore, we also excluded 202 individuals because of under-or over-reporting of energy intakes $( \pm 3$ standardized deviation). Finally, 2215 participants from wave 1, 1242 from wave 2, 1833 from wave 3, and 1218 from wave 4 were selected.

The study was approved by the research ethics committee of the Research Institute for Endocrine Sciences (RIES), Shahid Beheshti University of Medical Sciences, and written informed consent was obtained from the participants.

\section{Dietary assessment and food grouping}

In each wave to assess the regular dietary intakes of participants over the previous year, during face-to-face interviews, trained dieticians gathered dietary data using a validated and reliable food frequency questionnaire (FFQ), for each food item on the FFQ, a portion size was specified using US Department of Agriculture (USDA) serving sizes whenever possible; if this was not possible, household measures were chosen and were then converted to grams. Energy and nutrient contents of food items were obtained from USDA food composition tables (FCT) because Iranian FCTs are incomplete. The Iranian FCT was used for traditional food items that are not listed in the USDA FCT.

To identify dietary patterns, dietary data were categorized into 17 groups, based on food and nutrient composition similarity [15] as follows: (1) Whole grains; (2) Refined grains; (3) Potatoes; (4) Dairy products; (5) 
Vegetables; (6) Fruits; (7) Legumes; (8) Meats; (9) Nuts and seeds; (10) Solid fats; (11) Liquid oils; (12) Tea and coffee; (13) Salty snacks; (14) Simple sugars; (15) Honey and jams; (16) Soft drinks; and (17) Snacks and desserts.

\section{Measurements}

Height was measured by well-trained examiners which participants not wearing no shoes and was recorded to the nearest $0.5 \mathrm{~cm}$. Weight was measured using digital scales (Seca, Hamburg, Germany) and was recorded to the nearest $100 \mathrm{~g}$, while the subjects were minimally clothed and without shoes. Body mass index (BMI) was calculated as the weight divided by the square of the height $(\mathrm{kg} / \mathrm{m} 2)$. Waist circumference (WC) was measured at the level of the umbilicus to the nearest $0.5 \mathrm{~cm}$, using a measuring tape in the standing position.

\section{Statistical analysis}

All statistical analyses were performed using SPSS (version 16.0), with $P$-values $<0.05$ considered significant. Normality of the distribution of variables was assessed by the Kolmogorov-Smirnov test and checked by Histogram. As plasma TG was skewed, the log transformation was used. Characteristics of participants were expressed as mean \pm standard error (SE) for continuous variables and percentages for categorical variables. Generalized Estimating Equations (GEE) were used to assess secular trends in anthropometric, biochemical, and dietary variables across the years 2006 to 2017. Since the present study examined participants for a decade, all anthropometric measurements were adjusted for age, and nutrient intakes and dietary food groups were further adjusted for sex, BMI, and energy intakes of participants. Specifically, using GEE, anthropometric and nutritional variables were placed in dependent variables, and all the confounders were placed in the predictor's part (categorical variables in the fixed and continuous variables in covariate parts). Finally, the adjusted mean \pm SE of each variables were used as variable value. To identify dietary patterns during each separated examination wave, PCA was used, based on eigenvalues $>1$, scree plot and factor interpretability. Variables with factor loadings of $\geq 0.3$ were used in interpreting the factors. To assist interpretation, factors were rotated with the varimax procedure. Each dietary pattern was labeled by a descriptive name after the most important loading variables as "Western dietary pattern", "Healthy dietary pattern" and "Mixed dietary pattern". Finally, K-mean cluster analysis was used to assess the secular trend and adherence of dietary patterns among study population. In this method, three dietary patterns which were extracted from the PCA were added to the cluster analysis. Then, each participant give a specific score between 1 and 3 (based on the number of definite dietary patterns). Therefore, the percent of study population for each dietary pattern adherence can be calculated.

\section{Results}

Trends in anthropometric and biochemical parameters

Secular trends observed in anthropometric measurements during the four waves are shown in Table 1 . In the age-adjusted model, there was an increase in BMI and waist circumference from $26.5 \mathrm{~kg} / \mathrm{m}^{2}$ in wave 1 to $27.7 \mathrm{~kg} / \mathrm{m}^{2}$ in wave 4 and from $88.2 \mathrm{~cm}$ in wave 1 to $93.6 \mathrm{~cm}$ in wave 4 , respectively.

\section{Changes in nutrient and energy intake}

Table 2 shows the stability in total energy intakes among study population over the last decade. Moreover, percentage of energy from carbohydrate and protein intakes gradually increased $(P$-value $<0.001)$, whereas dietary total fat intake, saturated fatty acid, MUFA, and PUFA decreased slightly since the first wave (all P-value< 0.001). Interestingly, dietary sodium intake decreased from $2006 \mathrm{mg} / 1000 \mathrm{Kcal}$ in wave 1 to $1556 \mathrm{mg} / 1000 \mathrm{Kcal}$ in wave 4 (P-value $<0.001)$. Participants in wave 1 consumed $16.2 \mathrm{~g} / 1000 \mathrm{kcal}$ of dietary fiber which increased to $19.5 \mathrm{~g} / 1000 \mathrm{kcal}$ in wave 4 ; lastly, total sugar intake was remained stable throughout the study period.

\section{Changes in dietary food groups}

Figure 1 indicates food groups consumed among the population through the four waves. During the study period, participants consumed notably refined grains, solid fat, and simple sugar (all $P$-values $<0.001$ ). In addition, intakes of dairy products decreased significantly during the last decade (P-value $<0.001)$. During the study period, meat consumption had no significant changes among study participants. Interestingly, snack and dessert consumption increased rapidly, especially in the third wave (all P-values $<0.001$ ). Moreover, fruit and vegetable intake remained stable throughout the study period (data not shown).

\section{Changes in dietary patterns}

Table 3 shows the factor loading of food items throughout four waves. The first dietary pattern explored by PCA was the Healthy dietary pattern which was characterized by higher intakes of vegetable, fruit, dairy products, liquid oil, nuts and seeds, and honey and jam and this factor explained $12.0 \%$ of the variance; the second dietary pattern was the Western dietary pattern which was featured by refined grain, solid fat, meat, snack and dessert, potato, and soft drink and lastly and This factor explained $9.7 \%$ of the variance, the Mixed dietary pattern extracted was highlighted by tea and coffee, and simple sugar, explaining $8.2 \%$ of the variance. In the second wave, the 3 dietary patterns were changed as follow: 
Table 1 General characteristics of the study population throughout the four waves

\begin{tabular}{llllll}
\hline & $\begin{array}{l}\text { Wave1 } \\
(\mathbf{2 0 0 6 - 2 0 0 8 )}\end{array}$ & $\begin{array}{l}\text { Wave2 } \\
(\mathbf{2 0 0 9 - 2 0 1 1 )}\end{array}$ & $\begin{array}{l}\text { Wave3 } \\
\mathbf{( 2 0 1 2 - 2 0 1 4 )}\end{array}$ & $\begin{array}{l}\text { Wave4 } \\
\mathbf{( 2 0 1 5 - 2 0 1 7 )}\end{array}$ \\
\hline Participants $(\mathrm{n})$ & 2215 & 1242 & 1833 & 1218 & P for trend \\
Age (year) & $38.0 \pm 0.2$ & $39.6 \pm 0.3$ & $42.7 \pm 0.3$ & $46.2 \pm 0.3$ \\
Female (\%) & 52.7 & 54.0 & 52.4 & 51.1 & $<0.001$ \\
Waist (cm) & $88.2 \pm 0.2$ & $91.8 \pm 0.3$ & $92.5 \pm 0.3$ & $93.6 \pm 0.3$ & $<.001$ \\
Body mass index $\left(\mathrm{kg} / \mathrm{m}^{2}\right)$ & $26.5 \pm 0.1$ & $27.0 \pm 0.1$ & $27.4 \pm 0.1$ & $27.7 \pm 0.1<0.001$ \\
\hline
\end{tabular}

Values are expressed as age-adjusted mean \pm SE for continuous and percent for categorical variables. General estimate equation was used

first of all, meat, soft drink, and potato were added to the Healthy dietary pattern; secondly, people ate more legumes along with their Western dietary pattern; and finally, solid fat was concurrently expressed from Western to the Mixed dietary pattern, in comparison to the previous wave, participants in wave 3 modified their dietary patterns. Honey and jam intakes was not loaded in the Healthy dietary pattern, and potato intake shifted from the Healthy to the Western dietary pattern; the fourth wave, soft drink, meat, and potato intake were loaded in the Western dietary pattern. Interestingly, dietary refined grain has been shifted slightly from the Western to the Mixed dietary pattern. (The communalities of food groups in all the waves were shown in the supplementary Table 1).

\section{Adherence of study population to each dietary pattern}

Based on cluster analysis, the secular trends in dietary patterns are presented in Fig. 2; overall the trend showed a decline in the Western dietary pattern from $31.2 \%$ in wave 1 to $27.8 \%$ in wave 4 , and an increase in the Mixed dietary pattern from $29.7 \%$ in wave 1 to $34.1 \%$ in wave 4 . Finally, the Healthy dietary pattern remained stable among the study population during the last decade.

\section{Discussion}

In the present study which analyzed dietary data collected from four waves over the course of a decade (from 2006 to 2017), we derived three dietary patterns using factor analysis mostly centered on these food groups: 1. A Healthy dietary pattern, characterized by vegetable, fruit, dairy products, liquid oil, and nuts and seeds; 2. A Western dietary pattern featured by soft drinks, snack and dessert, meat, refined grain, and solid fat intake, and 3. A Mixed dietary pattern highlighted by tea and coffee, and simple sugars. Our findings indicated that the structure of these dietary patterns did not seem to be stable over a decade, indicating that the type of food groups that population chose to eat in combination had changed since 2006. Results demonstrating a secular trend in dietary patterns including an emerging adherence of study population to the Mixed dietary pattern, maintenance of the Healthy dietary pattern, and a decline in the Western dietary pattern.

Most previous epidemiological studies which focused on dietary patterns, have analyzed the relation of dietary pattern with risk of chronic diseases [16-21], and only a few of them have investigated the secular trend of dietary patterns over time $[9,10,22,23]$; mostly three common dietary patterns have been identified throughout

Table 2 Changes in nutrient and energy intake among study population over the four waves

\begin{tabular}{|c|c|c|c|c|c|}
\hline & $\begin{array}{l}\text { Wave1 } \\
(2006-2008)\end{array}$ & $\begin{array}{l}\text { Wave2 } \\
(2009-2011)\end{array}$ & $\begin{array}{l}\text { Wave3 } \\
(2012-2014)\end{array}$ & $\begin{array}{l}\text { Wave4 } \\
(2015-2017)\end{array}$ & P for trend \\
\hline Energy (Kcal) & $2383 \pm 19.8$ & $2518 \pm 27.3$ & $2396 \pm 24.6$ & $2282 \pm 30.3$ & 0.370 \\
\hline Carbohydrate (\% of energy) & $57.2 \pm 0.1$ & $58.7 \pm 0.2$ & $58.9 \pm 0.1$ & $59.7 \pm 0.1$ & $<0.001$ \\
\hline Protein (\% of energy) & $13.6 \pm 0.0$ & $14.8 \pm 0.0$ & $14.6 \pm 0.0$ & $15.1 \pm 0.1$ & $<0.001$ \\
\hline Fat (\% of energy) & $31.6 \pm 0.1$ & $29.8 \pm 0.1$ & $29.6 \pm 0.1$ & $29.1 \pm 0.1$ & $<0.001$ \\
\hline Saturated fatty acid (\% of energy) & $10.6 \pm 0.1$ & $9.8 \pm 0.0$ & $9.5 \pm 0.0$ & $9.3 \pm 0.0$ & $<0.001$ \\
\hline Monounsaturated fatty acid (\% of energy) & $11.0 \pm 0.0$ & $9.9 \pm 0.0$ & $9.8 \pm 0.0$ & $9.8 \pm 0.0$ & $<0.001$ \\
\hline Polyunsaturated fatty acid (\% of energy) & $6.6 \pm 0.0$ & $5.9 \pm 0.0$ & $5.9 \pm 0.0$ & $5.8 \pm 0.0$ & $<0.001$ \\
\hline Sodium (mg/1000Kcal) & $2006 \pm 31.9$ & $1529 \pm 12.3$ & $1537 \pm 11.4$ & $1556 \pm 12.2$ & $<0.001$ \\
\hline Dietary fiber (gr/1000Kcal) & $16.2 \pm 0.1$ & $19.4 \pm 0.2$ & $18.3 \pm 0.1$ & $19.5 \pm 0.2$ & $<0.001$ \\
\hline Total sugar (gr/1000Kcal) & $52.6 \pm 0.3$ & $53.0 \pm 0.3$ & $54.0 \pm 0.3$ & $55.0 \pm 0.3$ & 0.166 \\
\hline
\end{tabular}

Values are expressed as adjusted mean \pm SE. All variables were adjusted by age, sex, body mass index and energy intake. General estimate equation was used 


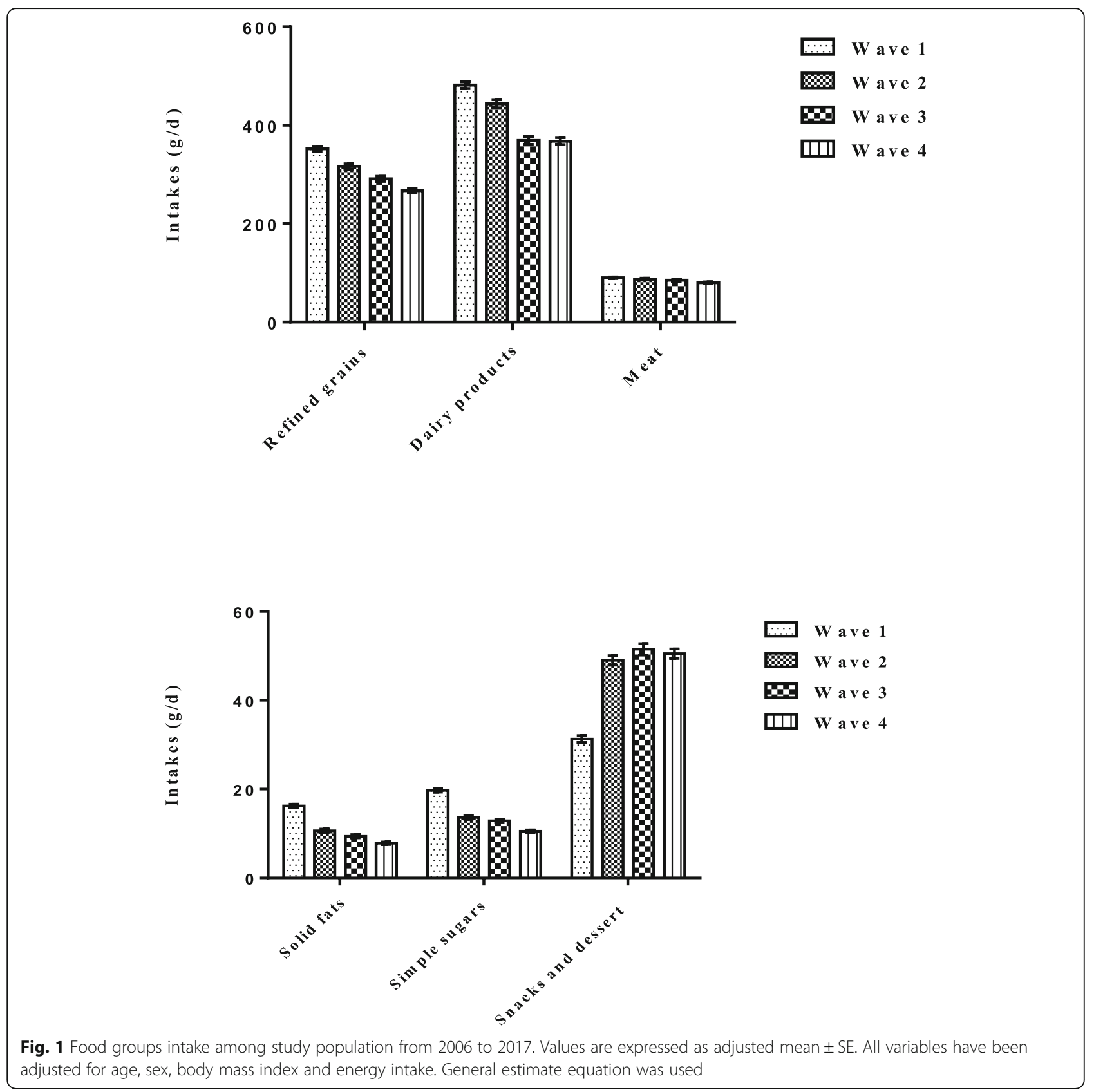

these investigations. The Healthy or Prudent dietary pattern which is mostly based on fruit, vegetables, dairy products, and liquid oil, Unhealthy or Westernized dietary pattern, mostly characterized by solid fat, snack, soda, and meat; however, the third one, mostly named as modified, new or mixed dietary pattern, differ in each study with different factor loading and food items. Results of the Healthy and Western dietary patterns loaded in the current study are mostly similar to other studies $[9,21]$. Adherence of our study population to the three dietary patterns is similar to those of a Korean population, in which the number of participants following the Western dietary pattern declined, and the new dietary pattern increased in population over time [10].

According to the results of this study, energy intakes of study population remained stable since the first wave. However, the percent of energy from carbohydrate and protein intakes increased whereas percent of energy from fat and all its subtypes (saturated, mono- and polyunsaturated fatty acids) decreased. People have become increasingly aware of the health benefits of vegetable oils and it seems that the sources of fat intake have changed 
Table 3 Food groups loadings for 3 dietary patterns found by principle component analyses among study population

\begin{tabular}{|c|c|c|c|c|c|c|c|c|c|c|c|c|}
\hline \multirow[t]{2}{*}{ Food groups } & \multicolumn{3}{|c|}{ Wave1 } & \multicolumn{3}{|c|}{ Wave2 } & \multicolumn{3}{|c|}{ Wave3 } & \multicolumn{3}{|c|}{ Wave4 } \\
\hline & $\mathrm{H}$ & W & $M$ & $\mathrm{H}$ & W & $M$ & $\mathrm{H}$ & W & $M$ & $\mathrm{H}$ & W & $M$ \\
\hline Vegetables & 0.591 & - & - & 0.631 & - & - & 0.513 & - & - & 0.693 & - & - \\
\hline Fruits & 0.683 & - & - & 0.685 & - & - & 0.621 & - & - & 0.682 & - & - \\
\hline Dairy products & 0.544 & - & - & 0.511 & - & - & 0.513 & - & - & 0.418 & - & - \\
\hline Liquid oils & 0.534 & - & - & 0.478 & - & - & 0.653 & - & - & 0.334 & - & - \\
\hline Nuts and seeds & 0.522 & - & - & - & - & - & 0.319 & - & - & 0.422 & 0.314 & - \\
\hline Honey and jams & 0.366 & - & - & 0.434 & - & 0.324 & - & - & - & 0.319 & - & 0.379 \\
\hline Soft drinks & - & 0.446 & - & 0.487 & - & - & 0.489 & - & 0.405 & - & 0.585 & - \\
\hline Snacks and desserts & - & 0.447 & - & - & 0.721 & - & - & 0.708 & - & - & 0.701 & - \\
\hline Meats & - & 0.459 & - & 0.407 & - & - & 0.460 & - & - & - & 0.383 & - \\
\hline Refined grains & - & 0.602 & - & - & 0.471 & - & - & - & 0.423 & - & - & 0.474 \\
\hline Potatoes & - & 0.446 & - & 0.447 & - & - & - & 0.372 & - & - & 0.503 & - \\
\hline Solid fats & - & 0.536 & - & - & - & 0.337 & - & - & 0.470 & - & - & 0.301 \\
\hline Salty snacks & - & 0.309 & - & 0.312 & - & - & - & - & - & 0.519 & - & - \\
\hline Simple sugars & - & - & 0.711 & - & - & 0.830 & - & - & 0.764 & - & - & 0.735 \\
\hline Tea and coffee & - & - & 0.765 & - & - & 0.747 & - & - & 0.586 & - & - & 0.574 \\
\hline Whole grains & - & - & - & - & 0.337 & - & - & - & - & - & - & - \\
\hline Legumes & - & - & - & - & 0.726 & - & - & 0.785 & - & - & 0.639 & - \\
\hline Cumulative variance $\%$ & 12.0 & 21.7 & 30.0 & 13.3 & 24.2 & 33.6 & 12.7 & 22.5 & 31.8 & 12.1 & 23.6 & 33.0 \\
\hline
\end{tabular}

Values less than 0.3 were excluded for simplicity

$H$ Healthy dietary pattern, $W$ Western dietary pattern, $M$ Mixed dietary pattern

during the last decade, with a significant shift from intakes of solid fat to the liquid oil [24]. Likewise, sources of protein intake have changed from animal to plant based, including legumes.

In term of the trend in food consumption, our findings indicate that fruit and vegetable intakes remained consistent, indicating that policy based-approaches must be considered to increase fruit and vegetable intakes, as consumption of these food groups is barely possible for populations with low income. Whole grain, increased significantly since the first wave, which was in contrast with the trend of other MENA region countries [4]. In the current study, intake of meat as a protein source was stable over the last decade, a finding contrary to the results of other Asian countries, including China and India, where meat intake had increased since westernization [25]. It is important to note that with the growing rate of urbanization, study population consume more snacks and desserts. One of the important points of the current study is that dietary dairy intakes decreased significantly throughout the waves; this finding has been confirmed by the World Health Organization

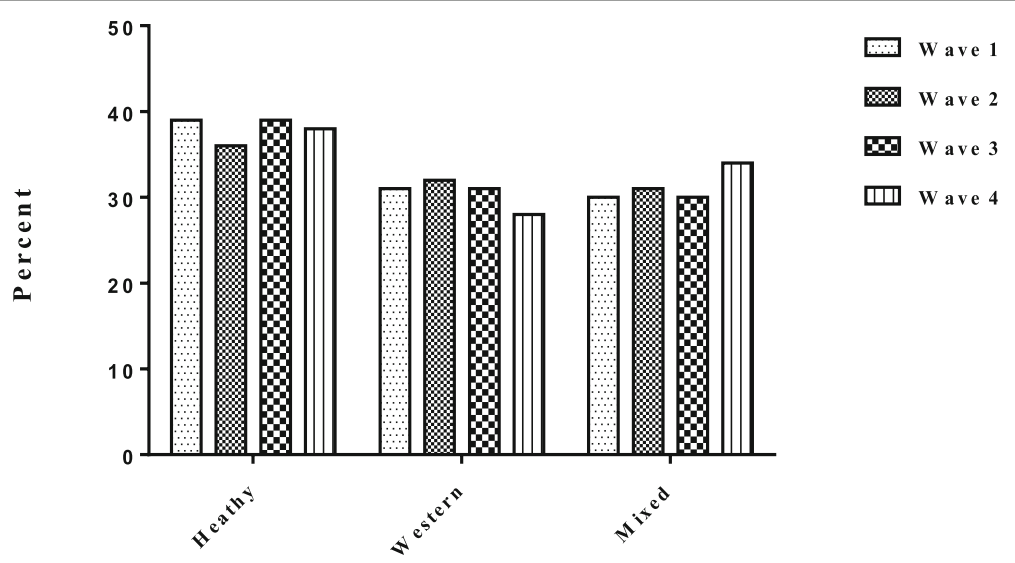

Fig. 2 Adherence to 3 dietary patterns among study population in Iran from 2006 to 2017. K-mean cluster analysis was used 
STEP wise approach to Surveillance (STEPS), which indicated that only approximately $18 \%$ of Iranian population meet the appropriate amount of dairy intakes [26].

Based on the results of the current study, the percent of study population who follow the Mixed dietary pattern has increased since the wave 1 ; this dietary pattern includes of simple sugar, tea and coffee, and whole grain, and is very similar to the traditional dietary pattern of Iranian population. Simple sugar and tea and coffee were loaded in all four waves, showing these food items to be deeply rooted in the traditional dietary pattern of Iranian culture. Interestingly, in the second and mostly the third wave unhealthy food items such as refined grain, and solid fat were added to the Mixed dietary pattern, possibly influence by modified Iranian meals like a western style dinner. The traditional Iranian diet is wheat-based. Tea is the major beverage and dairy products such as yoghurt and cheese was consumed widely [2]; however, the consumption of dairy products decreased since the previous decade. It is noteworthy that about $38 \%$ of our study populations try to maintain a healthy dietary pattern; however, intakes of food groups have changed and they accepted Western-style foods are more consumed, based on changing environmental factors, indicating that Iranians have modified their dietary pattern; in other words it is not totally westernized, although many of unhealthy foods have been added to the traditional dietary patterns of our study population.

The strength of the present study is as follow. Firstly, it was the first study investigating the secular trend of Iranian population dietary patterns and the adherence to these dietary patterns during the last decade. Secondly, the longitudinal design of the study, by which we could track changes in dietary patterns individually. Besides, we believe that our comparisons between years were not affected by the cohort effect, not only because all the subjects were included in at least two waves but also because we adjusted all the results by age in the first wave.

One of the limitations of the present study is that some food groups including dairy products and meat intakes were not categorized into subgroups. For example, dairy products include of low fat dairy, high fat dairy, or meats include of egg, red meat, processed meat, poultry, and fish. Therefore, it is not clear that higher factor loading of these food groups in one of the three dietary patterns is because of which sources of food items; however, we consider all the foods which were categorized in a same groups of the food pyramid. Another important limitation is that the number of foods available in the food supply exceeds by far the number of those available in food composition tables so the present study was unable to capture all the changes in dietary intake, particularly of packaged processed foods. Recall bias was also an inevitable problem when asking participants to remember and report dietary intakes. Finally, information about diet therapies for obesity had not been gathered by demographic questionnaire and was not in the scope of TLGS. Because of that we could not exclude participants with diet therapy for obesity.

\section{Conclusions}

Overall, it is clear that the structure and the type of foods that this population preferred to had changed since 2006. We report here in a new secular trend in dietary patterns, including a stability of the Healthy dietary pattern, a decline of the Western dietary pattern and an increase in the Mixed dietary pattern. These findings may recommend community policies on successful points, areas for greater attention, and opportunities to improve the dietary habits of the population living in Iran.

\section{Supplementary information}

Supplementary information accompanies this paper at https://doi.org/10. 1186/s12937-020-00624-X.

Additional file 1 Supplementary Table 1. Communalities of dietary

food groups in each wave of TLGS

\begin{abstract}
Abbreviations
BMI: Body mass index; BP: Blood pressure; DBP: Diastolic blood pressure; FBS: Fasting blood glucose; FCT: Food composition tables; FFQ: Food frequency questionnaire; GBD: Global Burden of Disease; GEE: Generalized Estimating Equations; MENA: Middle East and North Africa; PCA: Principle component analysis; SE: Standard error; STEPS: STEP wise approach to Surveillance; TC: Total cholesterol; TLGS: Tehran Lipid and Glucose Study; USDA: US Department of Agriculture; WC: Waist circumference
\end{abstract}

\section{Acknowledgements}

We would like to acknowledge Ms. Niloofar Shiva for a critical editing of English grammar and syntax of the manuscript.

\section{Authors' contributions}

All authors have read and approved the final manuscript. Overall P. M., G. A. supervised the project and approved the final version of the manuscript to be submitted. G. A. and M. A. designed the research; M. A. and E. Y. analyzed and interpreted the data; F. A. critically reviewed the manuscript; and M. M. drafted the initial manuscript statistical methodology.

\section{Funding}

This study was supported by the Shahid Beheshti University of Medical Sciences, Tehran, Iran (Grant no. 18492-1). The funder were not involved in the design of the study and collection, analysis, and interpretation of data and in writing the manuscript.

\section{Availability of data and materials}

All data generated or analyzed during this study are included in this published article.

\section{Ethics approval and consent to participate}

The design of this study was approved by the institutional ethics committee of the Research Institute for Endocrine Sciences, Shahid Beheshti University of Medical Sciences, and written informed consent was obtained from all study participants.

Consent for publication

Not applicable. 


\section{Competing interests}

The authors declare that they have no competing interests.

\section{Author details}

${ }^{1}$ Nutrition and Endocrine Research Center, Research Institute for Endocrine Sciences, Shahid Beheshti University of Medical Sciences, P.O. Box: 19395-4763, Tehran, Iran. ${ }^{2}$ Department of Clinical Nutrition and Dietetics, Faculty of Nutrition Sciences and Food Technology, National Nutrition and Food Technology Research Institute, Shahid Beheshti University of Medical Sciences, Tehran, Iran. ${ }^{3}$ Obesity Research Center, Research Institute for Endocrine Sciences, Shahid Beheshti University of Medical Sciences, Tehran Iran. ${ }^{4}$ Endocrine Research Center, Research Institute for Endocrine Sciences, Shahid Beheshti University of Medical Sciences, Tehran, Iran.

Received: 4 February 2020 Accepted: 11 September 2020 Published online: 03 October 2020

\section{References}

1. Galal O. Nutrition-related health patterns in the Middle East. Asia Pac J Clin Nutr. 2003;12.

2. Ghassemi H, Harrison G, Mohammad K. An accelerated nutrition transition in Iran. Public Health Nutr. 2002;5:149-55.

3. Popkin BM. Nutritional patterns and transitions. Popul Dev Rev. 1993:138-57.

4. Azizi F, Hadaegh F, Hosseinpanah F, Mirmiran P, Amouzegar A, Abdi H, Asghari G, Parizadeh D, Montazeri SA, Lotfaliany M. Metabolic health in the Middle East and North Africa. Lancet Diabetes Endocrinol. 2019.

5. results. GBoDs: Complementary feeding in the MENA region: Practices and challenges. http://ghdxhealthdataorg/gbd-results-tool 2017:(accessed March 20, 2019)

6. Kelly BB, Fuster V. Promoting cardiovascular health in the developing world: a critical challenge to achieve global health: National Academies Press; 2010.

7. Newby PK, Muller D, Hallfrisch J, Qiao N, Andres R, Tucker KL. Dietary patterns and changes in body mass index and waist circumference in adults. Am J Clin Nutr. 2003;77:1417-25.

8. Quatromoni P, Copenhafer D, Demissie S, D'agostino R, O'horo C, Nam B, Millen $B$, The internal validity of a dietary pattern analysis. The Framingham nutrition studies. J Epidemiol Community Health. 2002;56:381-8.

9. Batis C, Sotres-Alvarez D, Gordon-Larsen P, Mendez MA, Adair L, Popkin B. Longitudinal analysis of dietary patterns in Chinese adults from 1991 to 2009. Br J Nutr. 2014;111:1441-51.

10. Lim H, Kim SY, Wang Y, Lee SJ, Oh K, Sohn CY, Moon YM, Jee SH. Preservation of a traditional Korean dietary pattern and emergence of a fruit and dairy dietary pattern among adults in South Korea: secular transitions in dietary patterns of a prospective study from 1998 to 2010. Nutr Res. 2014; 34:760-70.

11. Soon JM, Tee ES. Changing trends in dietary pattern and implications to food and nutrition security in Association of Southeast Asian Nations (ASEA N). Int J Nutr Food Sci. 2014;3:259-69.

12. Leone A, Battezzati A, De Amicis R, De Carlo G, Bertoli S. Trends of adherence to the Mediterranean dietary pattern in northern Italy from 2010 to 2016. Nutrients. 2017;9:734.

13. Vandevijvere S, Monteiro C, Krebs-Smith S, Lee A, Swinburn B, Kelly B, Neal B, Snowdon W, Sacks G. Informas: monitoring and benchmarking population diet quality globally: a step-wise approach. Obes Rev. 2013;14: 135-49.

14. Azizi F, Ghanbarian A, Momenan AA, Hadaegh F, Mirmiran P, Hedayati M, Mehrabi Y, Zahedi-Asl S. Prevention of non-communicable disease in a population in nutrition transition: Tehran lipid and glucose study phase II. Trials. 2009:10:5.

15. Esfahani FH, Asghari G, Mirmiran P, Azizi F. Reproducibility and relative validity of food group intake in a food frequency questionnaire developed for the Tehran lipid and glucose study. J Epidemiol. 2010;20:150-8.

16. Sangsefidi ZS, Ghafouri-Taleghani F, Zakavi SR, Norouzy A, Kashanifar R, Pourbaferani R, Safarian M, Hosseinzadeh M. Major dietary patterns and differentiated thyroid cancer. Clin Nutr ESPEN. 2019.

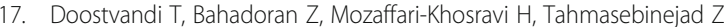
Mirmiran P, Azizi F. The association of dietary patterns and the incidence of insulin resistance after a 3-year follow-up: Tehran lipid and glucose study. Asia Pac J Clin Nutr. 2017;26:531.
18. Asadi Z, Shafiee M, Sadabadi F, Heidari-Bakavoli A, Moohebati M, Khorrami M, Darroudi S, Heidari S, Hoori T, Tayefi M. Association of dietary patterns and risk of cardiovascular disease events in the MASHAD cohort study. J Hum Nutr Diet. 2019.

19. Aljefree N, Ahmed F. Association between dietary pattern and risk of cardiovascular disease among adults in the Middle East and North Africa region: a systematic review. Food Nutr Res. 2015;59:27486.

20. Daniel CR, Cross AJ, Koebnick C, Sinha R. Trends in meat consumption in the USA. Public Health Nutr. 2011;14:575-83.

21. Pala V, Lissner L, Hebestreit A, Lanfer A, Sieri S, Siani A, Huybrechts I, Kambek L, Molnar D, Tornaritis M. Dietary patterns and longitudinal change in body mass in European children: a follow-up study on the IDEFICS multicenter cohort. Eur J Clin Nutr. 2013;67:1042.

22. Bermudez Ol, Tucker KL. Trends in dietary patterns of Latin American populations. Cad Saude Publica. 2003;19:S87-99.

23. Mikkilä V, Räsänen L, Raitakari O, Pietinen P, Viikari J. Consistent dietary patterns identified from childhood to adulthood: the cardiovascular risk in young Finns study. Br J Nutr. 2005;93:923-31.

24. Aryan Z, Mahmoudi N, Sheidaei A, Rezaei S, Mahmoudi Z, Gohari K, Rezaei N, Hajipour MJ, Dilmaghani-Marand A, Razi F. The prevalence, awareness, and treatment of lipid abnormalities in Iranian adults: Surveillance of risk factors of noncommunicable diseases in Iran 2016. J Clin Lipidol. 2018:12: 1471-1481. e1474.

25. Popkin BM, Horton S, Kim S, Mahal A, Shuigao J. Trends in diet, nutritional status, and diet-related noncommunicable diseases in China and India: the economic costs of the nutrition transition. Nutr Rev. 2001:59:379-90.

26. Ainy E, Mirmiran P, Mirsaied Ghazi AA, Mohammadi F, Azizi F. Daily intake and serum levels of calcium, phosphorus, magnesium and vitamin d during normal pregnancy. FEYZ. 2005;9:16-20.

\section{Publisher's Note}

Springer Nature remains neutral with regard to jurisdictional claims in published maps and institutional affiliations.
Ready to submit your research? Choose BMC and benefit from:

- fast, convenient online submission

- thorough peer review by experienced researchers in your field

- rapid publication on acceptance

- support for research data, including large and complex data types

- gold Open Access which fosters wider collaboration and increased citations

- maximum visibility for your research: over $100 \mathrm{M}$ website views per year

At $\mathrm{BMC}$, research is always in progress.

Learn more biomedcentral.com/submissions 